\title{
Preventing sudden unexpected postnatal collapse in term and late preterm newborn infants: a surveillance protocol
}

\author{
Riccardo Davanzo ${ }^{*}$ Laura Travan, Giuseppina Verardi, Elisa Corubolo, Angela De Cunto, Giulia Paviotti, \\ Tamara Strajn, Francesca Marrazzo, Pierpeolo Brovedani, Jaquelyn Kennedy, Enrica Causin, Sergio Demarini
}

From XX National Congress of the Italian Society of Neonatology

Rome, Italy. 9-11 October 2014

Early and prolonged skin-to-skin contact (SSC) after birth between a mother and her newborn has been shown to generate beneficial effects on mother-infant relationship and breastfeeding. SSC may ease the infant's transition to extra uterine life and helps to regulate the infant's body temperature and nursing behavior.

However, reports of sudden unexpected postnatal collapse (SUPC) soon after birth, in healthy term and late preterm neonates, in association with skin-to-skin contact, have raised concerns about the safety of this practice.

Based on the available evidence, the working group on breastfeeding of the Maternal and Child Health Institute of Trieste (Italy) developed a surveillance protocol to be implemented in the Delivery Room and Postnatal Ward. The aim of our protocol is: 1) promoting safe motherinfant bonding 2) establishing successful early breastfeeding and 3) correcting the risk factors for sudden unexpected postnatal collapse (SUPC). This protocol is especially focused on the first 2 hours of life, when about 1/3 of SUPC occur, but extends to the whole duration of the infant stay in the maternity ward.

The following interventions will be undertaken: 1. antenatal and early postnatal oral and written information to parents about: a) the risk of bed-sharing b) avoidance potentially suffocating infant positions (i.e. mouth/nose obstruction) c) the need of an adequate supervision of the infant in the first hours/days after birth 2. periodical assessment (position, colour, breathing) of the infant (at 10, 30, 60, 90 and 120 minutes of life) by midwives in the delivery room 3 . discouragement of bed-sharing 4. encouragement of skin-to-skin contact

\footnotetext{
* Correspondence: riccardo.davanzo@gmail.com

Perinatal Medicine, Institute for Maternal and Child Health IRCCS "Burlo Garofolo", Trieste, Italy
} and take full advantage of:

- Convenient online submission

- Thorough peer review

- No space constraints or color figure charges

- Immediate publication on acceptance

- Inclusion in PubMed, CAS, Scopus and Google Scholar

- Research which is freely available for redistribution

Submit your manuscript at 